\title{
Potent Induction of Apoptosis by $\beta$-Lapachone in Human Multiple Myeloma Cell Lines and Patient Cells
}

\author{
Youzhi Li, Chiang J. Li, Donghui Yu, and Arthur B. Pardee \\ Division of Cancer Biology, Dana-Farber Cancer Institute, and Department of \\ Biological Chemistry and Molecular Pharmacology, Harvard Medical School, \\ Boston, Massachusetts, U.S.A.
}

Accepted September 5, 2000.

\begin{abstract}
Background: Human multiple myeloma (MM) remains an incurable hematological malignancy. We have reported that $\beta$-lapachone, a pure compound derived from a plant, can induce cell death in a variety of human carcinoma cells, including ovary, colon, lung, prostate, pancreas, and breast, suggesting a wide spectrum of anticancer activity.

Materials and Methods: We first studied antisurvival effects of $\beta$-lapachone in human MM cells by colony formation assay. To determine whether the differential inhibition of colony formation occurs through antiproliferative activity, we performed MTT assays. The cytotoxicity of $\beta$-lapachone on human peripheral blood mononuclear cells was also measured by MTT assay. To determine whether the cell death induced by $\beta$-lapachone occurs through necrosis or apoptosis, we used the propidium iodide staining procedure to determine the sub-Gl fraction, Annexin-V staining for externalization of phosphatidylserine, and fragmentation of cellular genomic DNA subjected to gel electrophoresis. To investigate the mechanism of anti-MM activity, we examined $\mathrm{Bcl}-2$ expression, cytochrome $\mathrm{C}$ release, and poly
\end{abstract}

(ADP ribose) polymerase cleavage by Western blot assay.

Results: We found that $\beta$-lapachone (less than $4 \mu \mathrm{M}$ ) inhibits cell survival and proliferation by triggering cell death with characteristics of apoptosis in ARH-77, HS Sultan, and MM.1S cell lines, in freshly derived patient MM cells (MM.As), MM cell lines resistant to dexamethasone (MM.1R), doxorubicin (DOX.40), mitoxantrone (MR.20), and mephalan (LR5). Importantly, after treatment with $\beta$-lapachone, we observed no apoptosis in peripheral blood mononuclear cells in either quiescent or proliferative states, freshly isolated from healthy donors. In $\beta$-lapachone treated ARH-77, cytochrome $\mathrm{C}$ was released from mitochondria to cytosol, and poly (ADP ribose) polymerase was cleaved, signature events of apoptosis. Finally, the apoptosis induced by $\beta$-lapachone in MM cells was not blocked by either interleukin-6 or Bcl-2, which confer multidrug resistance in MM.

Conclusions: Our results suggest potential therapeutic application of $\beta$-lapachone against MM, particularly to overcome drug resistance in relapsed patients.

\section{Introduction}

Multiple myeloma is a malignancy that affects 14,400 new individuals in the United States annually (1). It is a malignant disease of plasma cells, manifested as excess monoclonal protein in blood and/or urine, bone marrow

Correspondence and reprint requests to: Youzhi $\mathrm{Li}$, Division of Cancer Biology, Dana-Farber Cancer Institute, and Department of Biological Chemistry and Molecular Pharmacology, Harvard Medical School, 44 Binney St., Boston, MA 02115, U.S.A. Phone (617) 632-3372; Fax: (617) 632-4680; E-mail: Youzhi_Li@dfci.harvard.edu plasmocytosis, anemia, renal dysfunction, bone lesions, and immunodeficiency. Despite the use of conventional and high dose chemotherapy, the median duration of survival is 6 months when no treatment is given. It remains a challenging disease for current drugs. Systematic chemotherapy is the main treatment, with which the current median survival is about 3 years, and fewer than $5 \%$ of patients live longer than 10 years (2). New biologically based chemotherapies are therefore urgently needed. 
$\beta$-Lapachone (3,4-dihydro-2,2-dimethyl-2Hnaphthol[1,2-b] pyran-5,6-dione), a simple nonwater-soluble orthonapthoquinone, was first isolated in 1882 by Paterno from the heartwood of the lapacho tree $(3,4)$. The structure was established by Hooker in 1896, and it was first synthesized by Fieser in 1927 (3). It can be obtained by simple sulfuric acid treatment of the naturally occurring lapachol, which is readily isolated from Tabebuia Avellanedae growing mainly in Brazil, or is easily synthesized from seeds of lomatia growing in Australia (5), plants so abundant that their wood is used for furniture, and leaves for beverage tea. It has been shown to have a variety of pharmacological effects. Numerous derivatives have been synthesized and tested as antiviral and antiparasitic agents, and it also has antitrypanosomal effects (6-8), the mechanism of which is unclear. It significantly prolongs the survival of mice infected with Rauscher leukemia virus, probably through inhibition of reverse transcriptase $(7,9)$. We have demonstrated that $\beta$-lapachone inhibits viral replication and gene expression directed by the long terminal repeat (LTR) of the human immunodeficiency virus type I (8).

$\beta$-Lapachone was investigated as a novel and potent DNA repair inhibitor that sensitizes cells to ionizing radiation and DNA damaging agents $(10,11)$. We have reported that it and its derivatives inhibit eukaryotic topoisomerase I through a different mechanism than does camptothecin, which may be mediated by a direct interaction of $\beta$-lapachone with topoisomerase I rather than stabilization of the cleavable complex (12). This unique mode of action and chemical structure of $\beta$-lapachone motivated us to test the sensitivity to this compound of a variety of human cancer cell lines both in vitro and in vivo (13). We (22) and others have reported that it induces cell death in human prostate cancer cells. Furthermore, we found that it induces necrosis in human breast cancer cells, and apoptosis in ovary, colon and pancreatic cancer cells through induction of caspases (13).

$\beta$-Lapachone is well tolerated in dogs, rats, mice, and chickens. The maximum tolerated dose, when given p.o. daily for 1 month, is $200 \mathrm{mg} / \mathrm{kg}$ in rats, and $100 \mathrm{mg} / \mathrm{kg}$ in dogs. Higher doses cause gastric ulceration and loss of erythrocytes, but not signs of bone marrow suppression (Ciba-Geigy, personal communication; Li et al., manuscript in preparation).

In the present study, we observed that $\beta$ lapachone suppresses survival and prolifera- tion by triggering typical apoptosis in human multiple myeloma (MM) cells including drugsensitive cells and freshly derived MM cell from patients, but not of normal peripheral blood mononuclear cells (PBMCs). Importantly, this effect of $\beta$-lapachone was also observed in MM cell lines that are resistant to drugs. $\beta$-Lapachone induced apoptosis in MM cells, which was preceded by a rapid release of cytochrome $\mathrm{C}$, followed by the activation of caspase and poly (ADP) ribose polymerase (PARP) cleavage. The sensitivity to $\beta$ lapachone was not affected by expression of Bcl-2, a key mediator of drug resistance in myeloma cells $(14,15)$. Exogenous interleukin6 (IL-6), an important anti-apoptotic factor for MM cells (16), did not dampen the apoptotic effect of $\beta$-lapachone. This study therefore suggests that $\beta$-lapachone is a potential new drug for treating human multiple myeloma.

\section{Materials and Methods}

\section{Chemicals}

$\beta$-Lapachone was kindly provided by Dr. A. V. Pinto. It was dissolved at $20 \mathrm{mM}$ concentration in dimethyl sulfoxide (DMSO), aliquoted, and stored at $-20^{\circ} \mathrm{C}$ for cell culture use.

\section{Cell Cultures}

All cells used in this study were kindly provided by Dr. Kenneth Anderson (Department of Adult Oncology, Dana-Farber Cancer Institute, Boston, MA, USA). ARH-77 was obtained from ATTC, DOX40, MR20, and LR5 from Dr. W. Dolton, and MM.1S and MM.RI from Dr. S. Roon. MM.As are a MM patient's cells. MM.1R, DOX.40, and MR.20, and LR5 are resistant to dexamethasone, doxorubicin, mitoxantrone, and melphalan, respectively. Cells were maintained at $37^{\circ} \mathrm{C}$ in $5 \% \mathrm{CO}_{2}$ in $100 \%$ humidity, and were cultured in RPMI1640 medium (Life Technologies Inc.), supplemented with $10 \%$ FCS, 2 mM L-glutamine.

\section{Colony Formation Assay}

Exponentially growing cells were seeded at 2,000 cells/well in six-well plates and were allowed to attach for $48 \mathrm{~h}$. Drugs were added directly in less than $5 \mu \mathrm{l}$ of concentrated solution (corresponding to a final DMSO concentration of less than $0.1 \%$ ). Control plates received the 
same volume of DMSO alone. After $24 \mathrm{~h}$, cells were rinsed, and fresh medium was added. Cultures were observed daily for 10 to 20 days, and then were fixed and stained with modified Wright-Giemsa stain (Sigma Co., St. Louis, MO, USA). Colonies of greater than 30 cells were scored as survivors.

\section{Cell Proliferation Assay}

Cell proliferation was determined by ${ }^{3} \mathrm{H}-$ thymidine uptake assays and the 3-[4,5dimethylthiazol-2-yl]-2,5-diphenyltetrazolium bromide (Thiazolyl blue, MTT) assay (Sigma Co.). The conversion of the soluble yellow dye to the insoluble purple formazan by the mitochondrial dehydrogenase of viable cells was used for measurement of cell proliferation (17). Briefly, cells were plated in a 96-well plate at 20,000 cells/well, cultured for $48 \mathrm{~h}$ in complete growth medium, then treated with $\beta$-lapachone for $24 \mathrm{~h}$. MTT solution $(5 \mathrm{mg} / \mathrm{ml})$ was added in $1 / 10$ of culture volume to the culture medium, and after 3 to $4 \mathrm{~h}$, the converted dye was solubilized with acidic isopropanol and optical density was read with an ELISA reader at a wavelength of $570 \mathrm{~nm}$ with a background subtraction at 630-690 nm (17). For the ${ }^{3} \mathrm{H}$-thymidine uptake assays, cells were pulsed with ${ }^{3} \mathrm{H}$-TdR (Dupont, Wilmington, DE, USA; $0.5 \mu \mathrm{Ci} /$ well) during the last $6 \mathrm{~h}$ of 1-day cultures, harvested onto glass filters by use of a HARVESTAR 96 MACH II (Tomtec, Orange, CT, USA) cell harvester, and counted on a 1205 Betaplate (Gaithersburg, MD, USA) scintillation counter $(1,18)$.

\section{Apoptosis Assay}

Apoptosis was determined by three independent assays. One determined the sub-Gl fraction by propidium iodide staining of nuclei as described previously $(13,19,20,22)$. The second measured the membrane changes determined by the externalization of phosphatidylserine $(13,21)$. Briefly, cells were treated with $\beta$ lapachone for $24 \mathrm{~h}$, harvested, washed in PBS, resuspended in binding buffer, incubated with annexin V-FITC, and analyzed by flow cytometry. The third assay, by DNA laddering, was carried out as described $(19,20,22)$.

\section{Western Blot Analysis}

Whole cell lysate and S-100 fraction were prepared from exponential growing cells. The ECL assay system was used for detection of Bcl-2 levels, cytocrome $\mathrm{C}$ released from mitochondria
(S-100 fraction), and PARP immunoblot analyses. Briefly, cell lysate protein samples were electrophoresed on a sodium dodecyl sulfatepolyacrylamide gel and then electrophoretically transferred to nitrocellulose membranes. The blots were blocked, washed, and incubated with the Bcl-2 antibody (Oncogene Science), Cambridge, MA, USA or using anti-PARP monoclonal antibody (Pharmingen, San Diego, CA, USA) at 1:1000 dilution. The filter was then incubated with a second antibody conjugated to horseradish peroxidase. Finally, the filter was developed with detection reagents (RPN 2109; Amersham) and exposed to a hyperfilm-ECL (RPN 2103). Cytochrome C release was carried out as previously described (13).

\section{Results}

Ablation of Colonies in Human MM Cells by $\beta$-Lapachone

To test the antisurvival effect of $\beta$-lapachone, drug-sensitive human MM cell line ARH-77, and DOX40 doxorubicin resistant cells were treated with $\beta$-lapachone in vitro. Cell survival was determined by colony-formation assay $\beta$-lapachone decreased cell survival in both cell lines with an IC90 of $4 \mu \mathrm{M}$ (Fig. 1).

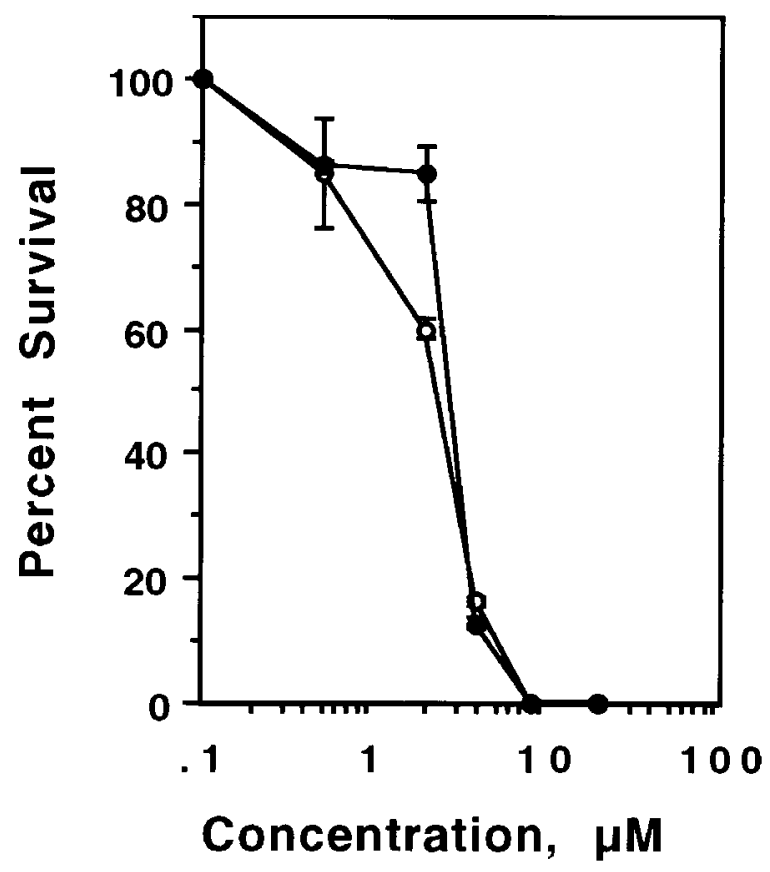

Fig. 1. Inhibition of colony formation by $\beta$-lapachone in human multiple myeloma cells. $\bigcirc$ ARH-77; Dox.40. Cell survival was determined by colony formation assay, as described in Materials and Methods. 
Differential Effect of $\beta$-Lapachone on Proliferation of MM Cells Versus Normal PBMC

To determine whether the differential inhibition of colony formation occurs through anti proliferative activity, proliferation of MM cells cultured in the absence or presence of $\beta$-lapachone $(2,4$, 8 , and $20 \mu \mathrm{M}$ ) for $24 \mathrm{~h}$ was measured by MTT assay. At a concentration of $4 \mu \mathrm{M}$, the MTT in cultures were evaluated and found to be significantly decreased in all seven MM cell lines (Fig. 2). There was also a dramatic reduction in the proliferation of patient's MM cells (MM.As) and the drug-resistant MM cells (MMI.R, DOX40, MR.20). No cross-resistance was observed. The same results could be seen by ${ }^{3} \mathrm{H}$-thymidine uptake assay (data not shown).

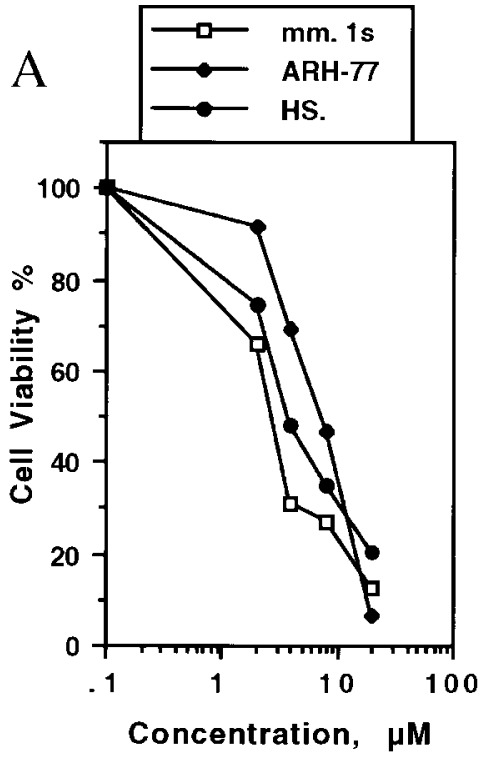

D

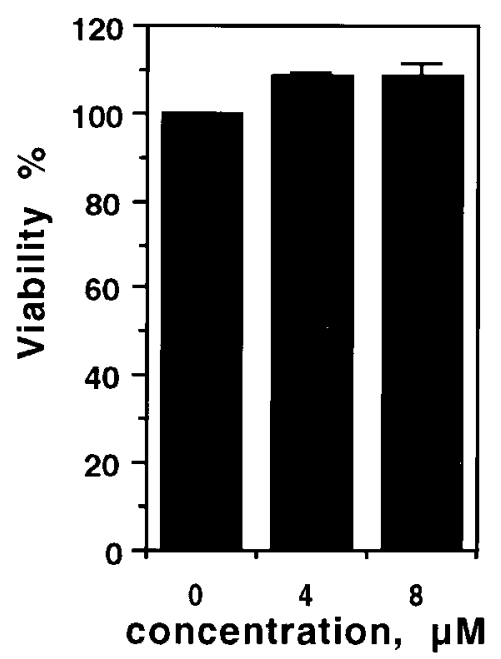

Fig. 2. Differential effect of $\beta$-lapachone on proliferation of multiple myeloma (MM) cells vs. normal PBMC. Proliferation of MM cells, quiescent peripheral blood mononuclear cells (PBMC) and proliferative PBMC cultured in the absence of or with $\beta$-lapachone $(0.5,2,4,8$, or $20 \mu \mathrm{M})$ for $24 \mathrm{~h}$ was measured by MTT assay. Cells used include in: (A) ARH-77, MM.1S and

$\mathbf{E}$
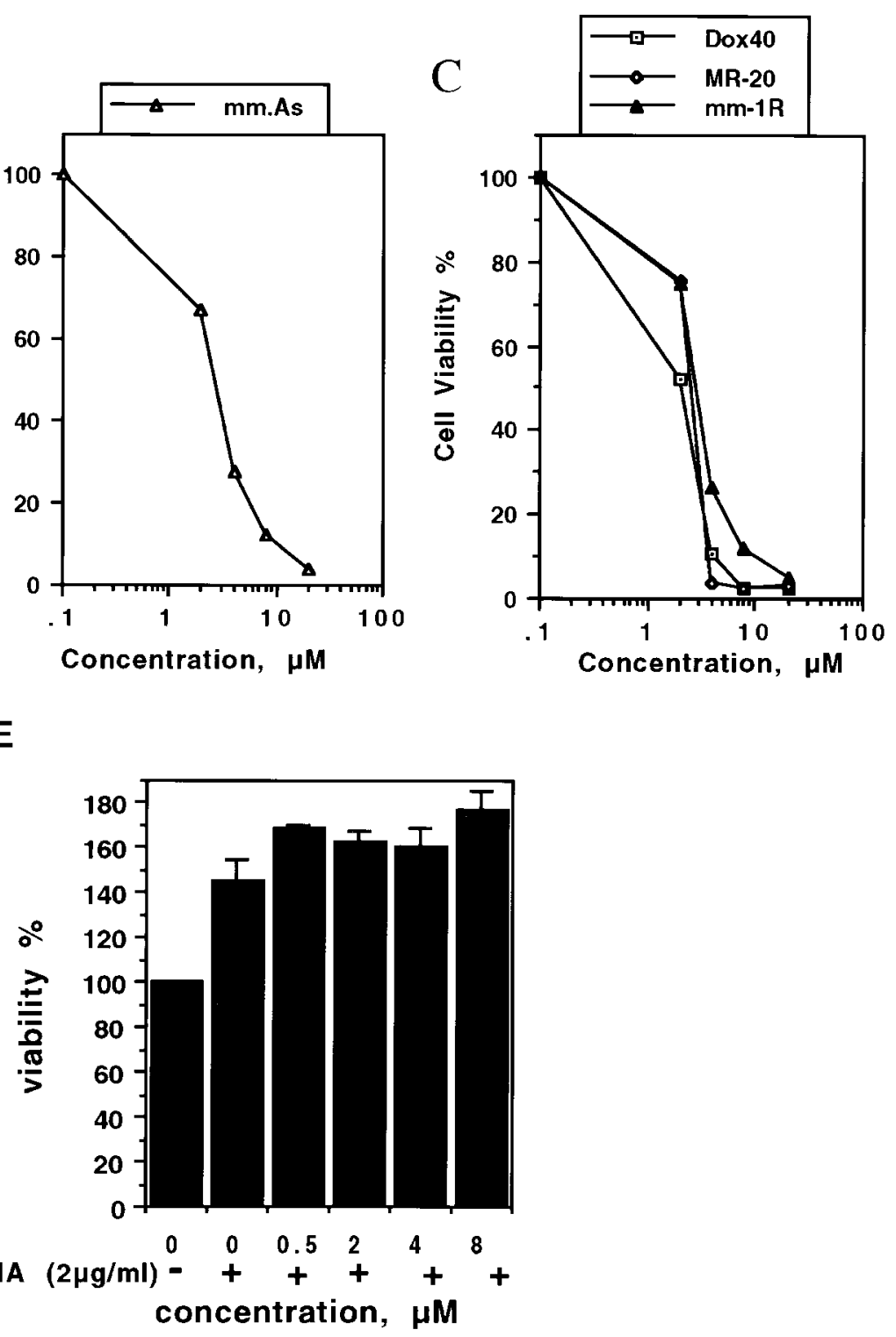

HSSultan (sensitive MM cell lines), (B) MM.As (MM patient cell), (C) MM.1R, DOX.40, MR.20 and LR5 (resistant MM cell lines), (D) quiescent PBMC, (E) proliferating PBMCs (generated by $72 \mathrm{~h}$ incubation with PHA at $2 \mu \mathrm{g} / \mathrm{ml}$ ). In the absence of $\beta$-lapachone, cells were treated with an equal volume of dimethyl sulfoxide. 
To investigate the cytotoxicity of $\beta$-lapachone on human PBMC, the cells were isolated from anticoagulant-treated blood. Proliferating PBMC were generated by $72 \mathrm{~h}$ incubation with phytohemagglutinin (PHA) at $2 \mu \mathrm{g} / \mathrm{ml}$ (24). Growth of cells cultured in the absence or presence of $\beta$-lapachone $(0.5,2,4$, and $8 \mu \mathrm{M})$ for $24 \mathrm{~h}$ was measured by MTT. No cytotoxity to either fresh or proliferating PBMC growth was observed (Fig. 2).

\section{Induction of Apoptosis by $\beta$-Lapachone}

To determine whether the extensive cell death observed in proliferating human MM cells after treatment with $\beta$-lapachone is due to apoptosis or necrosis, we performed three independent assays. First, cellular genomic DNA was subjected to gel electrophoresis, after $24 \mathrm{~h}$ drug exposure. As shown in Figure 3, $\beta$-lapachone induced DNA laddering typical of apoptosis.
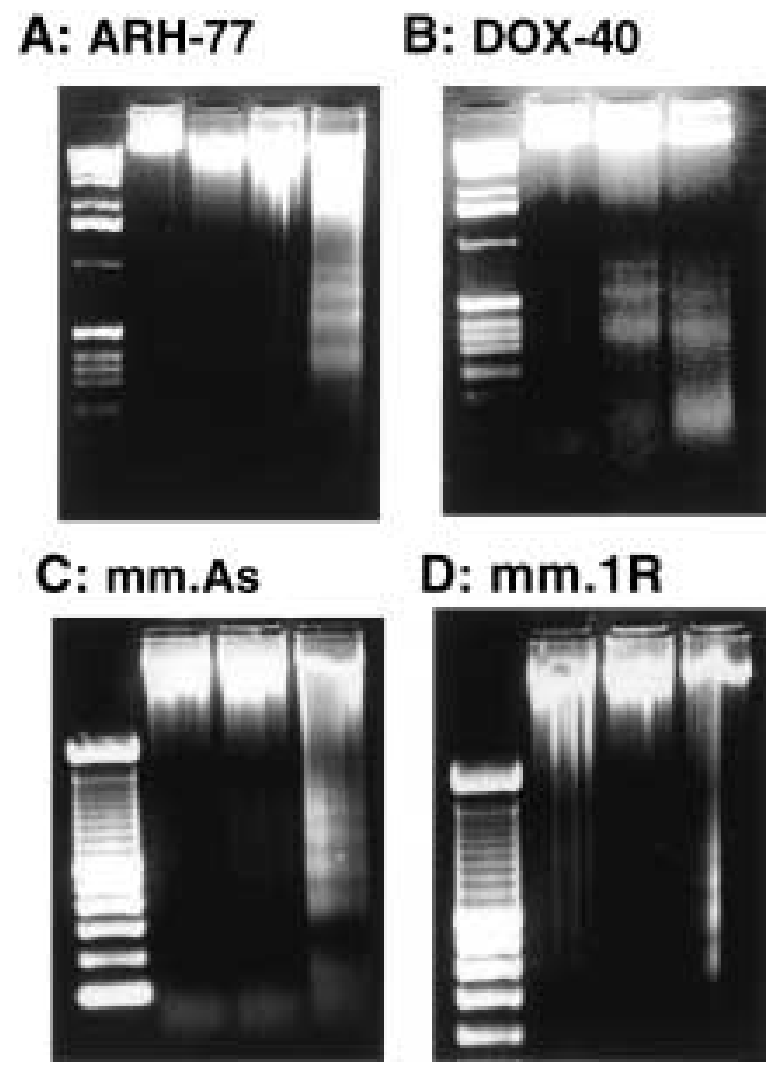

Fig. 3. Induction of DNA fragmentation by 0 , 2, 4, $8 \mu \mathrm{M} \beta$-lapachone in human multiple myeloma (MM) cells. DNA laddering, a typical feature of apoptosis, was induced in: (A) ARH-77 treated with $\beta$-lapachone, (B) RPMI DOX-40, (C) MM.AS, (D) MM.1R. After exposure to the drug for $24 \mathrm{~h}$, genomic DNA was extracted and subjected to agarose gel electrophoresis (19).
Second, we used PI staining to determine the sub-Gl fraction as a test for apoptosis. As shown in Figure 4A, $\beta$-lapachone treatment produced an increased fraction of sub-Gl cells. In the third assay, we determined externalization of phosphatidylserine, as measured by Annexin-V staining of these cells (Fig. 4B). The percentage of Annexin $\mathrm{V}$ positive cells also increased with treatment, correlating with the sub-Gl fractions. All these results show that $\beta$ lapachone induced apoptotic death of these MM cells.

Apoptosis Induced by $\beta$-Lapachone Is Independent of Expression of Bcl-2, Is Preceded by Cytochrome

$C$ Release, and Is Followed by PARP Cleavage

Expression of Bcl-2 has been implicated in the resistance of cancer cells including MM cells to chemotherapeutic drugs $(14,15)$. To determine whether apoptosis induced by $\beta$-lapachone in MM cells is due to lack of or altered Bcl-2 expression, we applied Western blot assays. Bcl2 was expressed in ARH.77 and MM1.R cells and was not changed by $\beta$-lapachone (data not shown). Therefore, Bcl-2 expression did not correlate with sensitivity to $\beta$-lapachoneinduced apoptosis.

To determine if $\beta$-lapachone triggers cytochrome $\mathrm{C}$ release, a marker of apoptosis, $\mathrm{MM}$ ARH77 cells were analysed for cytoplasmic cytochrome $\mathrm{C}$ at $2 \mathrm{~h}$ after drug treatment. As shown in Figure 5A, cytochrome $\mathrm{C}$ was released into cytoplasm shortly after $\beta$-lapachone treatment when cells were fully viable by trypan blue exclusion and MTT assay, suggesting that cytochrome $\mathrm{C}$ release is an early event in apoptosis of MM cells induced by $\beta$-lapachone. Next we examined whether $\beta$-lapachone induces PARP cleavage, a hallmark of apoptosis that indicates activation of caspase. As expected, two fragments corresponding to the remaining intact PARP protein (116 KDa) and the typical apoptotic $85 \mathrm{KDa}$ fragment were visualized (Fig. 5B).

\section{Discussion}

Multiple myeloma is a drug-sensitive disease but the majority of patients with MM acquire resistance to conventional therapy and relapse (2). Since the introduction of melphalan and prednisone therapy for MM, numerous multidrug chemotherapies have been tested including Vinca 
A:

\section{ARH-77 mm1.S mm1.R}

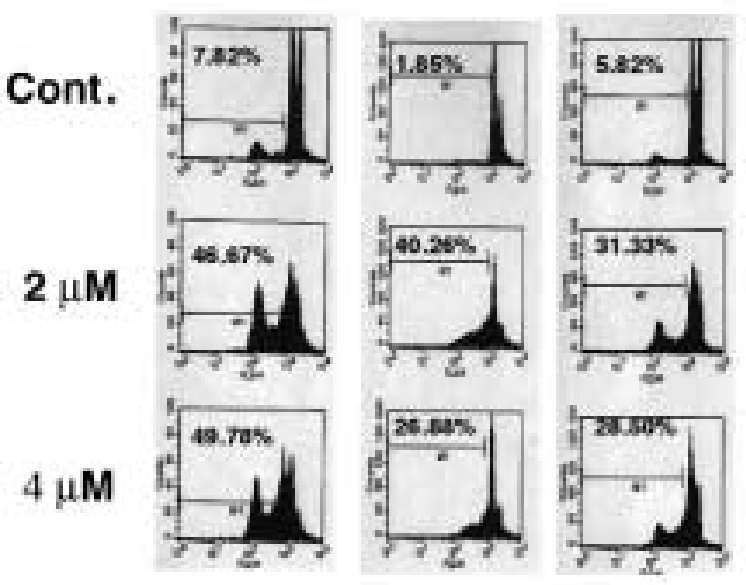

Fig. 4. Induction of apoptosis by $\beta$-lapachone in human multiple myeloma (MM) cells. Human ARH-77, MM1.S, and MM1.R cells were treated with $\beta$-lapachone, $0 \mu \mathrm{M}$ (DMSO), $2 \mu \mathrm{M}$, or $4 \mu \mathrm{M}$, for $24 \mathrm{~h}$. They were then subjected to flow cytomet-

alkaloids, anthracycline, and nitrosourea-based treatment (24), but there has been little improvement in outcome over the past three decades (24,25). Although high-dose therapy may achive higher response rates overall, and event free survival, few if any patients are cured. Thus, new agents to overcome the resistance to currently applied chemotherapeutic agents and to improve outcomes are urgently needed.

Previously we found that $\beta$-lapachone in moderate dose, when combined with taxol, has effective anti-tumor activity in a human ovarian, prostate, and breast cancer xenograft models in nude mice. No signs of toxicity to the mice were observed, and no weight loss was

\section{A: ARH-77}

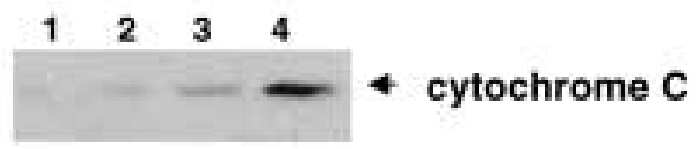

\section{B: ARH-77}

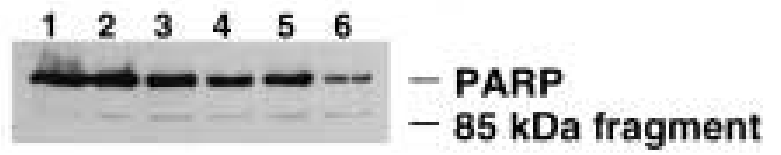

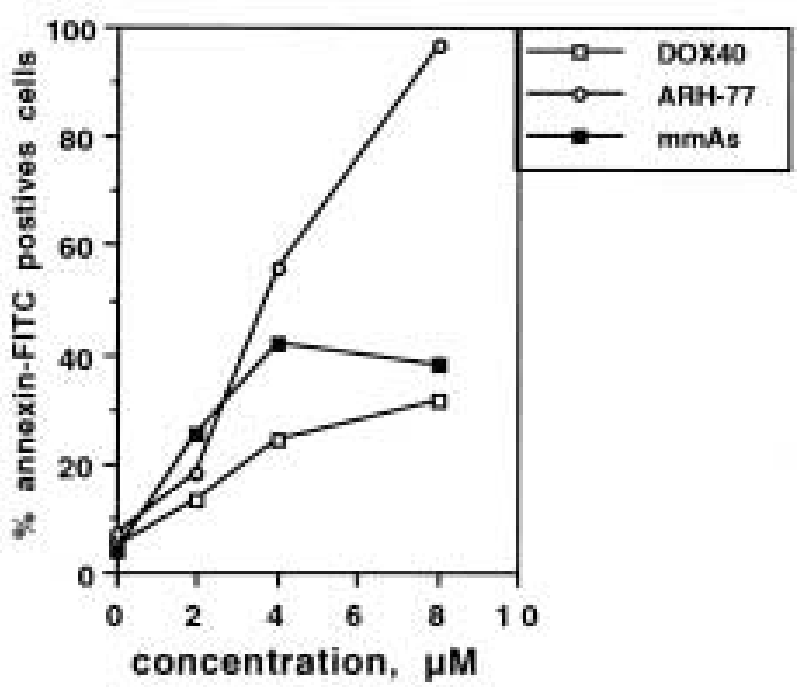

ric analysis after staining with propidium iodide for quantitating the (A) sub-Gl fraction, or for the (B) analysis of externalization of phosphatidylserine, as measured by Annexin V staining ( $\square$ DOX-40,

ARH-77, MM.AS).

recorded during the subsequent 2 months following treatment during which the tumors did not reappear (20). Based on these observations, we suggested the potential of $\beta$-lapachone as a new cancer chemotherapy agent. Now we show that it has considerable promise for treatment of MM patients.

In this study, we have tested a variety of human MM cells for their sensitivity to $\beta$-lapachone. Human MM cells were more sensitive to $\beta$-lapachone than PBMCs; there was no cell death effect on PBMC from healthy donors. No cross-resistance was found with cell lines resistant to corticosteroids, anthracycline, and alkylating agents, the most commonly used agents

Fig. 5. Apoptosis induced by $\beta$-lapachone is accompanied by mitochondrial cytochrome $C$ release and poly (ADP ribose) polymerase (PARP) cleavage. (A) ARH-77 cells were treated with dimethyl sulfoxide (DMSO) (lane 1) or $\beta$ lapachone at $4 \mu \mathrm{M}$ for $0.5 \mathrm{~h}$ (lane 2 ), $2 \mathrm{~h}$ (lane 3), or $4 \mathrm{~h}$ (lane 4). Mitochondrial cytochrome $\mathrm{C}$ release was determined by Western blot assay, as described in Materials and Methods. (B) ARH-77 cells were treated with DMSO (lane 1) or $\beta$-lapachone at $2 \mu \mathrm{M}$ for $2 \mathrm{~h}$ (lane 2), $6 \mathrm{~h}$ (lane 3), $12 \mathrm{~h}$ (lane 4 ), $24 \mathrm{~h}$ (lane 5), or $48 \mathrm{~h}$ (lane 6). Immunoblot analyses of the lysates were performed with anti-PARP antibody. 
against MM. Moreover, neither Bcl-2 expression nor exogenous IL- 6 protected against apoptosis induced by $\beta$-lapachone. This apoptosis in MM cells was correlated with release of cytochrome $\mathrm{C}$, as with gamma irradiation, but in contrast to dexamethasone (K. Anderson, personal commu-nication), and was confimed by PARP cleavage. These results combine to suggest that cyto-chrome $\mathrm{C}$ release plays an important role in the mechanism of caspase activation, PARP cleavage, DNA fragmentation and the eventual apop-tosis induced by $\beta$-lapachone in MM cells.

The molecular mechanism of the observed apoptotic effect of $\beta$-lapachone remains to be determined. DNA topoisomerase $\mathrm{I}$ is a potential candidate. Induction of cell death by $\beta$ lapachone was associated with cell cycle delays at Gl and S phase, unlike most DNA damaging agents which arrest cancer cells at the G2/M transition. This artificially imposed G1/S checkpoint delay by $\beta$-lapachone precedes p53-independent (20) apoptotic or necrotic cell death in a variety of human carcinoma cells in vitro. Both apoptotic and necrotic cell death induced by $\beta$-lapachone are preceded by a rapid release of cytochrome $C$, followed by activation of caspase 3 in apoptotic cell death but not in necrotic cell death (13). Further studies are needed to define the molecular target for $\beta$ lapachone induced apoptosis.

\section{Acknowledgments}

We thank Dr. Kenneth Anderson for providing MM cells and for critically reading the manuscript. This work was supported in part by Grant RO1 CA61253 from the National Institutes of Health.

\section{References}

1. Treon SP, Teoh G, Urashima M, Ogata A, Chauhan D, Webb J, Anderson K. (1998) Antiestrogens induce apoptosis of multiple myeloma cells. Blood 92: 1749-1757.

2. Anderson K, Kyle RA, Berenson JR, Dalton WS.(1999) Recent Advances in the Biology and Treatment of Multiple Myeloma. Annual Meeting Report 1999.

3. Hooker SC. (1936) Lomatiol. Part II. Its occurence, constitution, relation to and conversion into lapachol. Also a synthesis of lapachol J. Am. Chem. Soc. 58: 1181-1190.
4. Goncalves de Lima $\mathrm{O}, \mathrm{D}^{\prime}$ Albuquerque IL, Goncalves de Lima C, Dalla Maia MH. (1962) Substancias antimicrobianas de plantas superiores. Rev. Inst. Antibiot. Univ. Recife. 4: 3-17.

5. Li CJ, Averboukh L, Pardee AB. (1993) Betalapachone, a novel DNA topoisomerase I inhibitor with a mode of action different from camptothecin. J. Biol. Chem. 268: 22463-22468.

6. Goncalves AM, Vasconcellos ME, Docampo R, Cruz NS, Souza WR, Leon W. (1980) Evaluation of the toxicity of 3-allyl- $\beta$-lapachone against trypanosoma cruzi bloodstream forms. Mol. Biochem. Parasitology. 1: 167-176.

7. Schaffner-Sabba K, Schmidt-Ruppin KH, Wehrli W, Schuerch AR, Wasley JWF. (1984) $\beta$ Lapachone: synthesis of derivatives and activities in tumor models. J. Med. Chem. 27: 990-994.

8. Li CJ, Zhang LJ, Dezube BJ, Crumpacker CS, Pardee AB. (1993) Three inhibitors of type I human immunodeficiency virus long terminal repeat-directed gene expression and virus replication. Proc. Natl. Acad. Sci. USA. 90: 1839- 1842.

9. Schuerch AR, Wehrli W. (1978) $\beta$-Lapachone, an inhibitor of oncornavirus reverse transcriptase and eukaryotic DNA polymerase- $\alpha$. Eur. J. Biochem. 84: 197-205.

10. Boorstein RJ, Pardee AB. (1984) $\beta$-Lapachone greatly enhances MMS lethality to human fibroblasts. Biochem. Biophys. Res. Commun. 118: 828-834.

11. Boothman DA, Trask DK, Pardee AB. (1989) Inhibition of potentially lethal DNA damage repair in human tumor cells by $\beta$-lapachone, an activator of topoisomerase I. Cancer Res. 49: 605-612.

12. Li CJ, Averboukh L, Pardee AB. (1993) $\beta$ Lapachone, a novel DNA topoisomerase I inhibitor with a mode of action different from camptothecin. J. Biol. Chem. 268: 22463-22468.

13. Li YZ, Li CJ, Pinto AV, Pardee AB. (1999) Release of mitochondrial cytochrome $\mathrm{C}$ in both apoptosis and necrosis induced by $\beta$-lapachone in human carcinoma cells. Molec. Med. 5: 232-239.

14. Tu Y, Xu FH, Liu J, Vescio R, Berenson J, Fady C, Lichtenstein A. (1996) Upregulated expression of BCL-2 in multiple myeloma cells induced by exposure to doxorubicin, etoposide, and hydrogen peroxide. Blood 88: 1805-1812.

15. Bloem A, Lockhorst H. (1999) Bcl-2 antisense therapy in multiple myeloma. Pathol. Biol. (Paris) 47: $216-220$.

16. Anderson K. (1999) Advances in the biology of multiple myeloma: therapeutic applications. Sem. Oncol. 26(suppl 13): 10-22.

17. Mosmann T. (1983) Rapid colorimertic assay for cellular growth and survival: application to proliferation and cytotoxicity assays. J. Immunol. Meth. 65: 55.

18. Anderson K. (1999) Introduction. Sem. Oncol. 26: 1. 
19. Li CJ, Friedman DJ, Wang C, Metelev V, Pardee AB. (1995) Induction of apoptosis in uninfected lymphocytes by HIV-1 tat protein. Science 268: 429-431.

20. Li CJ, Li YZ, Pinto AV, Pardee A. (1999) Potent inhibition of tumor survival in vivo by $\beta$ lapachone plus taxol: combining drugs imposes different artificial checkpoints. Proc. Natl. Acad. Sci. USA 96: 13369-13374.

21. Zhang G, Gurtu V, Kain SR, Yan G. (1997) Early detection of apoptosis using a fluorescent conjugate of annexin V. BioTechniques 23: 525-531.

22. Li CJ, Wang C, Pardee AB. (1995) Induction of apoptosis by $\beta$-lapachone in human prostate cancer cells. Cancer Res. 55: 3712-3715.
23. Rita S, Michele R, Patrizia O, Alessandra B, Sara B, Enrico G. (1994) Inhibition of protein kinase $\mathrm{C}$ in PHA-activated PBMC treated with antiHLA class I monoclonal antibody is associated to decreased proliferation and expression of cell cycle related genes. Biochem. Mol. Biol. Int. 32: 105-114.

24. Case DC, Jr., Lee, DJ III, Clarkson BD. (1977) Improved survival times in multiple myeloma treated with melphalan, prednisone, cyclophosphamide, vincristine and BCNU: M-2 protocol. Am. J. Med. 63: 897-903.

25. Otsuki T, Yamada O, Kurebayashi J, et al. (2000) Estrogen receptors in human myeloma cells. Cancer Res. 60: 1434-1441. 